\title{
EL IMPERIO DE LA LEY Y EL PROBLEMA DE LA LEGISLACIÓN
}

\author{
Joaquín Almoguera Carreres \\ Universidad Pontificia Comillas
}

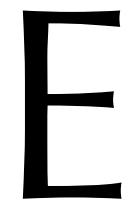

n cierta ocasión, un conocido, con experiencia en cuestiones académicas, me comentó que uno de los medios más seguros para quedar mal con un amigo consistía en participar en alguno de los actos organizados para celebrar su jubilación o algún otro acontecimiento de importancia. Sobre todo, si se trata de una aportación escrita para un futuro libro homenaje. Y ello, no tanto porque muestren su desagrado ante la contribución, o hagan una crítica excesiva, ya que, al fin y al cabo, como amigos, suelen ser considerados y, en todo caso, les bastaría con mostrar un distante agradecimiento. El problema no viene tanto del homenajeado como del participante en el acto, pues por regla general es difícil que uno mismo quede satisfecho de su trabajo y le parezca a la altura de las personas a las que se pretende celebrar; es decir, que uno siempre piensa que se ha quedado corto, comparado con los consejos, aclaraciones, atenciones, que ha recibido de aquellos a lo largo de su vida profesional.

Me temo que este es el caso de las líneas que siguen a continuación. Hecha esta cautela y como el que avisa no es traidor, permítaseme iniciar esta modesta aportación.

No me parece que tenga demasiado interés investigar el origen del término «izquierda» en política. Es posible que venga utilizándose hace dos siglos o siglo y medio, en España al menos. Parecen más relevantes los contenidos a los que ha estado vinculado. Sin pretender un análisis o un estudio exhaustivo, que podría ser interesante pero que creo ya está hecho, la palabra «izquierda» se ha conectado con el liberalismo, el progresismo (sea lo que sea), la democracia. En el siglo XIX se vinculó al socialismo, especialmente con el científico, separándose así del anarquismo, y dentro de aquel, con los intérpretes de su creador: MARX; dado que la doctrina se había construido con la pretensión de sintetizar teoría y práctica, siguiendo la huella de la doctrina hegeliana, aparecieron el leninismo, el trotskismo, el estalinismo, el maoísmo. Todo lo cual era expresión de las dudas que suscitaba su cientificidad y las consecuencias de su realización. Pero en la segunda posguerra, el panorama se complica aún más, aunque con interpretaciones más heterodoxas del marxismo anterior. Los marcusianos, althuserianos (que eran lo más cuando entré en el Departamento de la Universidad Autónoma, en ese momento dirigido por Paco LAPORTA a la espera de la incorporación de Elías DíAZ), habermasianos...

Este panorama, prolijo e insuficientemente recogido aquí, me resulta cercano al de la reflexión de la teoría jurídica. Tal vez podría haberse abordado la cuestión desde 
otro ángulo distinto del de «las izquierdas», pero este ofrece dos características que me interesa resaltar (y tampoco es que valga cualquier cosa): su carácter reductivo y exclusivista: la vida es poder y solo poder; es una estructura histórica material impersonal, es producción de plusvalor..., y su carácter combativo: siempre hay un rival, un polo al que enfrentarse y desautorizar, sea, en este caso, el Derecho natural o el formalismo. De manera que nos encontramos en un panorama igualmente complejo: el iusnaturalismo, el positivismo, con diferentes versiones, incluso con una teoría jurídica marxista, que reproduce muchas de las interpretaciones mencionadas.

El objetivo, ahora, tampoco es entrar en el análisis, inevitablemente apresurado, de estas concepciones jurídicas, sino señalar un tercer factor de familiaridad entre estos dos planteamientos generales: el afán metodológico, que en buena medida es también aquí el objetivo: dotar de carácter científico al Derecho. No es el momento de discutir aquí la metodología científico natural que se tomó como base (también se ha hecho en numerosas ocasiones, desde KIRCHMANN); pero sí el de subrayar las exigencias básicas que comportaba, como la regularidad o la previsibilidad. Desde este ángulo, puede decirse que la historia de la jurisprudencia desde el siglo XIX alemán, fue la lucha contra la contingencia; contenidos materiales, circunstancias histórico-sociales, valores, debían ser controlados o, en su caso, eliminados. Formalismos jurídicos de diferentes facturas descoyuntaron el Derecho en un contenido variable y unas formas constantes, lo que, como ha advertido GONZÁLEZ VICÉN, recordaba demasiado a la versión racionalista del Derecho natural.

El verdadero punto de inflexión en esta línea fue KELSEN. El normativismo, en efecto, representa el intento más completo de superar la epistemología anterior; en lugar de pensar la forma jurídica como originalmente separada, centrándose en formas abstractas capaces de reprimir la materialidad del Derecho (como IHERING), KELSEN se propone pensar la forma jurídica como una existencia objetiva, de manera que la norma constituiría un conjunto objetivo de significados. En el marco general del positivismo, convierte el Derecho en un sistema de cualificaciones normativas cuya objetividad depende de las condiciones formales de su producción. Como la objetividad no es, entonces, material, la obligatoriedad es solo hipotético-deductiva, derivando la objetividad de la cualificación, o sea, la validez, de una existencia específica: «Ser producido en cierta forma». El inconveniente es que, aunque objetivo, el valor es relativo, en cuanto puesto; la ventaja es que una vez puesto es objetivo.

En esta conquista del positivismo radica un aspecto del problema de la legislación que motiva, en el fondo, estas líneas. La norma es una obligación, un deber ser, un valor; pero un valor que adquiere validez objetiva gracias a un proceso de atribución formal que hace que un valor subjetivo de justicia se cualifique como objetivo. Así, la justicia solo puede conocerse como legalidad. KELSEN legitima la contingencia normativa. Si me queda un número suficiente de palabras, volveré sobre este tema.

Ahora es preciso insistir en la pluralidad de las teorías jurídicas. Ante la imposibilidad de formular un modelo epistemológico alternativo al kelseniano, el análisis lingüístico ofrece un modelo practicable, en el que, en cuanto análisis del lenguaje, no prejuzga la existencia de prácticas no teóricas sobre el derecho cuyo empirismo sostiene el positivismo: elimina el temor al positivismo desde el positivismo mismo. 
Pero nos situamos ya en la segunda posguerra. Siempre me ha parecido que la cuestión de la contribución del positivismo a los horrores de la guerra y de los regímenes que la provocaron es más ideológica que real. Pero es cierto que este periodo trajo importantes novedades. Las nuevas constituciones introdujeron, junto a las garantías liberales tradicionales, otros derechos que ya no se satisfacían con la no abstención y la protección, sino que suponían la realización de prestaciones concretas para los ciudadanos, y por tanto, la intervención del Estado en su vida real. De esta manera, el positivismo se vio rodeado de valores y principios. De modo que así como desde la izquierda, el cierto momento «todo era poder», en el Derecho, «todo son valores».

Y no se trataba de valores externos al Derecho, cuya existencia todos los positivistas admitían, sino de valores que se instalaban en el corazón mismo de lo jurídico. No son declaraciones programáticas formuladas con buenas intenciones, junto al núcleo duro de la constitución que es la organización del poder y sus competencias, sino de verdadero «Derecho». Porque, además, se cae en la cuenta de que las constituciones son normas, y todo su contenido, por ideal y bienintencionado que nos parezca, exigible y obligatorio. Los valores, convertidos en principios, exigen su satisfacción cada vez en mayor número y contenidos más novedosos (como los derechos de «últimas generaciones»). Independientemente de que algunos celebraran la situación como un nuevo retorno del Derecho natural (otro más), imponía nuevos retos a los juristas, muchos de ellos de formación positivista. El constitucionalismo o neoconstitucionalismo planteaba problemas que requerían nuevos instrumentos.

Se suscitaban dos clases de grandes problemas: el de la interpretación y el de la aplicación del Derecho. El concepto mismo de lo jurídico dependía de cómo se entendieran las nociones de «valor» o «principio». Así que se multiplicaron los trabajos en esta dirección: desde la reformulación de la regla jurídica en términos de optimización, o la conceptualización de los nuevos derechos, hasta las particularidades de la interpretación constitucional frente a la legal, pasando por la centralidad de la labor judicial y sus dificultades. Y en cuanto a la lista de autores, sería inmensa: prácticamente, hoy no falta nadie que no haya tratado esta cuestión en algún momento y bajo alguna perspectiva (de modo que mejor no intentar reproducirla, pues siempre se me pasará alguno sin querer). Pero un grupo ha puesto el acento en los principios originales del Derecho moderno (el Estado de Derecho, la división de poderes...).

En fin, alguien tenía que poner las cosas en su sitio, pues, como decía ATIENZA (en diálogo con LAPORTA, Isonomía, 31, 2009): «Las nuevas constituciones sí cambian el Derecho de forma sustancial». Y, en esta situación, se retoma, desde varias instancias, la noción que planteara en su momento Elías DíAz del imperio de la ley. Liborio HiERRo lo justificaba por lo que llamaba la crisis de la ley, esto es, la proliferación y variabilidad de las leyes, las normas paralegales, el carácter expansivo de las constituciones, y el valor de los principios («El imperio de la ley y la crisis de la ley», Doxa, 19, 1996). Por su parte, LAPORTA publica El imperio de la ley: una visión actual (Madrid, 2007), haciendo la noción equivalente a las de rule of law o Estado de Derecho, y, por tanto, como un principio de defensa frente a la arbitrariedad y la inseguridad, y relacionándola con el control del poder por el Derecho. De esta manera, y creo que este es el núcleo de su tesis, el imperio de la ley tiene una carga ética que va más allá 
de la cualidad formal de la existencia del Derecho: es un principio moral que no se identifica con la legalidad; mejor dicho, es la legalidad en cuanto conjunto de exigencias morales.

El fundamento moral del principio se sitúa en la autonomía de la persona, en la dignidad del hombre como ideal moral, que se expresa con fuerza en la Ilustración. LAPORTA no ignora que esta concepción choca con la existencia de normas que se nos imponen y nos someten, y es lo que, precisamente, exige justificar el poder político-jurídico, algo que se ha hecho, bien por motivos prudenciales, que convierten al Derecho en un monopolio de la fuerza, o bien por razones éticas, fundadas en las consecuencias indeseables del mecanismo totalizador del poder. Dichas razones, siempre según LAPORTA, se resumen en el imperio de la ley, los derechos del hombre y el principio democrático, teniendo el primero un sentido particularmente importante, al afectar al comportamiento y planes de vida (tanto para facilitarlos como para obstaculizar algunos). En resumen, o bien tomamos el Derecho como un objeto fijo, de donde viene el gobierno de las leyes, o como contingente, de donde deriva el decisionismo.

Así concebido, el imperio de la ley, que tiene en cuenta esa moralidad interna (FULLER) que se especifica en la normatividad, generalidad, publicidad..., pero también la aplicación del derecho según procedimientos establecidos (imparcialidad, la necesidad de argumentación...), constituye un horizonte conceptual diferente del de las doctrinas constitucionalistas. En su opinión, estas últimas no alteran la concepción positivista construida en el siglo XX, aunque introduzcan nuevos elementos, como el lenguaje de los valores y su aplicabilidad directa. Pues la constitución no ha inventado el Derecho, y constituye un grave error rechazar el legalismo positivista (acusado de rígido y formalista), para sustituirlo por un constitucionalismo también positivista, centrado en la no menos rígida sumisión a la misma. Así que el imperio de la ley trata de poner en sus justos términos los ingredientes valorativos, el garantismo, y otros postulados morales. Pero también evita que el sometimiento del juez a la norma, uno de los factores capitales del imperio de la ley, se relaje excesivamente, en la medida en que el juez Hércules crea más problemas de los que soluciona. Y, por último, el descrédito de que la ley es la emanación de la voluntad general no se arregla considerando que la constitución es la que nos obliga a cambiar nuestras teorías sobre el Derecho; es más bien al revés: el alto nivel de la teoría jurídica lleva a una nueva visión de la constitución. Pero en modo alguno, podría concluirse, el imperio de la ley es una alternativa al constitucionalismo. Solo pone el acento, cabría añadir, en que la ley no está para lograr cualquier cosa, ya que las razones para actuar de manera solo conforme, no se reducen a la simple satisfacción de deseos e intereses (L. HiERRO, La eficacia de las normas jurídicas, Barcelona, 2003).

Estamos ante un problema que se viene arrastrando desde tiempo atrás, como se ha advertido, desde la propia formación del positivismo. Suele ser cierto aquello de «eso ya lo habían dicho»; pero también es cierto que en estos casos se nos remonta a momentos y contenidos que no suelen tener nada que ver con el tema. Pero en este caso es cierto también que hay pensadores, fundadores, que sí habían visto el problema de cómo la ley podía provenir de la libertad (autonomía) del individuo y, al mismo tiempo, constituir su limitación: la ley debía ser algo prodigioso. No es casual que un tema recurrente en la Ilustración y en su puesta en práctica sea, precisamente, el de la 
legislación: SAVIGNY (era «la vocación de nuestro tiempo»), BENTHAM... O que ATIENZA comente que el Estado de Derecho parezca haber tenido más fortuna en diseñar las instituciones judiciales que las legislativas (cit.) El problema, tal y como lo conocemos fue diseñado por ROUSSEAU y KANT originalmente.

Teniendo en cuenta que me quedan 768 palabras para concluir esta contribución, me limitaré a una breve consideración del problema solo en ROUSSEAU y no en KANT. Tal vez haya otra ocasión para entrar en ambos. Moviéndonos en el terreno fronterizo de la filosofía jurídica y política, el centro del problema lo ocupa, evidentemente, la noción de contrato social. El hombre, había advertido RousSEAU, solo debe obedecerse a sí mismo, pero no en cuanto individuo aislado, sino como dependiente de instituciones en las que él mismo se reconoce, En ellas, no puede haber elementos personales, de manera que únicamente el acuerdo colectivo puede conseguir esta impersonalidad: la institución depende de la norma general ante la que todos son iguales. Al contrario que en KANT, que concibe la dependencia de las instituciones desde la distinción entre política y moral, ROUSSEAU admite que la persona vive regulada por el Derecho, pero que esta constituye la más alta regulación del sujeto, siendo también ética. La vida del hombre, pues, no será sentimental, sino republicana: la de la colectividad basada en la virtud.

Esto llevará a ROUSSEAU a entender el querer como saber de sí mismo, de modo que el objeto del querer significará quererse a sí mismo en el mundo: el yo en su universalidad. La voluntad se universaliza, y así, no contradice la voluntad absoluta propia de la voluntad general. El sujeto colectivo realiza esta totalidad: el pueblo, con lo que el pacto es un acto de voluntad que se disuelve en la generalidad del querer. Esto es, gracias al pacto, cada uno se enajena en la comunidad al poner su persona (y bienes) en común, bajo la voluntad general (por cierto que KANT transformará esta unión de voluntades, como condición a priori de la sociedad, en principio trascendental).

La sociedad surge del pacto, que es producto de la voluntad. Pero el resultado es el consenso, que proviene, a su vez, de la unidad y la concordia. Así, el pacto es una obligación de cada uno frente a todos, y de todos frente a cada uno. Aunque RousSEAU no habla de consenso, sino de convención, para subrayar la aceptación de las consecuencias del acuerdo. Esto permite comprender que el cuerpo social se funda sobre derechos que la voluntad general tiene, es decir, en la obligación que vincula indisolublemente al sujeto con el cuerpo colectivo, y no en una voluntad anterior a la unión.

Así, el cuerpo es una persona, y no una máscara superpuesta, como en HOBBES. $\mathrm{El}$ acto creador es el pacto, no la ley; esta se limita a animar un cuerpo que ya existe, dándole movimiento y voluntad, pues el acto inicial no determina qué debe hacer para conservarse. KANT mismo dirá que dicho pacto podría considerarse como ley fundamental, del Estado, pero no como una constitución en el sentido de una ley moderna. El pacto, pues, crea al pueblo sin obligar ni ordenar a nada, porque el pueblo ya está dotado de una voluntad.

En la ejecución de Luis XVI se pone de manifiesto que el rey no puede ser juzgado, como un ciudadano, al estar fuera de la comunidad. Esto revela que ROUSSEAU no puede considerarse iusnaturalista: el Derecho natural ni vincula ni juega ningún papel, 
al ser la sociedad completamente nueva. Pero el problema está, entonces, en la construcción del legislador, pues al coincidir con la voluntad general, no es materializable, de modo que (y este es el apresurado punto al que quería llegar) el legislador es parte, como uno de los poderes, y todo, como voluntad general, a la vez. Queridos HIERRO y LAPORTA, no me quedan más palabras; en algún otro momento y lugar intentaré ampliar y cerrar el discurso. 